\title{
Ordu ilindeki sığırcılık işletmelerinin ırk tercihinin ve önemli sorunlarının belirlenmesi*
}

\section{Determination of breed preference and important problems of cattle enterprises in Ordu province}

\author{
Sezai ALKAN ${ }^{1}$ (i), Zeki GÜNEY ${ }^{2}$ [i] \\ ${ }^{1}$ Ordu Üniversitesi, Ziraat Fakültesi, Zootekni Bölümü, ORDU \\ ${ }^{2}$ Ünye Tarım ve Orman İl Müdürlüğü, ORDU \\ Sorumlu yazar (Corresponding author): S. Alkan, e-posta (e-mail): sezaialkan61@gmail.com \\ Yazar(lar)e-posta (Author e-mail): zeciguney@hotmail.com
}

\section{MAKALE BİLGİSİ}

Alınış tarihi 08 Ocak 2020

Düzeltilme tarihi 25 Şubat 2020

Kabul tarihi 26 Şubat 2020

\section{Anahtar Kelimeler:}

Ordu ili

Sığırcılık işletmesi

Irk tercihi

Sorun

\begin{abstract}
ÖZ
Bu araştırmada, Ordu ilindeki sığırcılık işletmelerindeki sığır ırklarının ve önemli sorunlarının belirlenmesi amaçlanmıștır. Araş̧ırmada Ordu ilinin merkezinde ve ilçelerinde bulunan 517 adet sığırcılık işletmesinde yapılan anketlerden elde edilen veriler kullanılmışıır. Anket yapılan işletmeler hayvan sayılarına göre $\leq 5$ büyükbaş, 6-15 büyükbaş, 16-29 büyükbaş ve $\geq 30$ büyükbaş olmak üzere dört gruba ayrılmıştır. Araştırmada, işletmelerde kullanılan hayvanların \%45.07'sini melez, \%31.53'ünü yerli ve \%14.12'sini ise kültür rrklarının oluşturduğu saptanmıştır. İșletmelerin en önemli sorunları yem fiyatlarının yüksek olmas (\%48.55) ve ürünlerin fiyatına satılamaması (\%34.43) olarak belirlenmiştir.
\end{abstract}

\section{ARTICLE INFO}

Received 08 January 2020

Received in revised form 25 February 2020

Accepted 26 February 2020

\section{Keywords:}

Ordu province

Cattle enterprise

Breed presence

Problem

\begin{abstract}
The aim of this study was to determine the animal breeds and important problems of cattle enterprises in Ordu province. In the study, data that were obtained by conducting surveys in 517 cattle farms located in the center and districts of Ordu province were used. The surveyed enterprises were divided into four groups according to the number of animals that they have; $\leq 5$ cattle, $6-15$ cattle, $16-29$ cattle and $\geq 30$ cattle. In the research, $45.07 \%$ of the animals used in enterprises were cross-bred, $31.53 \%$ were domestic and $14.12 \%$ were culture breeds. The most important problems of the enterprises are the high feed prices $(48.55 \%)$ and not being able to sell products at a value price $(34.43 \%)$.
\end{abstract}

\section{Giriş}

İnsanların sağlıklı ve dengeli beslenebilmelerinde hayvansal kaynaklı proteinler önemli bir yer tutmaktadır. Yapılan birçok çalışmada yetişkin bir insanın günde $70 \mathrm{~g}$ proteine ihtiyacı olduğu ve bu ihtiyacın yaklaşık olarak \%40'ının hayvansal kaynaklı proteinlerden karşılanması gerektiği ortaya konulmuştur (Alkan ve Güney 2019; Alkan ve Ünlü 2019).Yeterli ve dengeli beslenmede önemli rolü bulunan hayvancılık sektörü milli geliri ve istihdamı artırmasının yanında birim yatırıma yüksek katma değer kazandırması, çeşitli sanayi dallarına hammadde sağlaması ve kalkınmaya katkıda bulunması açısından büyük önem taşımaktadır (İçöz 2004). Ayrıca, hayvancılık kırsal alandaki açık ve gizli işsizliğin azaltılmasında ve kırsaldan şehirlere olan göçün önlenmesinde önemli bir yer tutmaktadır. Türkiye'de hayvancılık işletmelerinin çoğu geleneksel uygulamalardan vazgeçerek modern işletmelere sahip olmuş bulunmaktadır. Sığırcılık işletmelerinin modernleşmesi küresel rekabete ayak uydurabilmeleri açısından günümüzde bir zorunluluk haline gelmiştir.

Sığırcılık faaliyetleri uzun zaman gerektirmekte olup faaliyete başlandıktan yapılan yatırımların başka yatırımlara çevrilmesi oldukça zor olmaktadır. Bundan dolayı da yetiştiricilerin hayvancılığı bırakıp başka sektörlere geçmeleri kolay olmamaktadır (Şahin ve Yılmaz 2008). Sığırcılık faaliyetinde yöre şartlarına uygun hayvan ırklarının seçilmesi yanında, ișletmenin mevcut kapasitesi, yetiștiricilerin bilinç düzeyi, sürü yönetimi, barınak şartları, işgücünün niteliği, besleme teknikleri ve sağlık koruma gibi etmenler üretimi 
doğrudan etkilemektedir. Üretimde sağlanan teknik başarı, işletme karlılığını ve verimliliği doğrudan etkilemektedir (Demir ve ark. 2013).

Türkiye'de artan nüfus ve yükselen sosyo-ekonomik refaha bağlı olarak hayvansal ürünlere olan talebin giderek artmas1, üretim ve verimliliğin artırılmasını da gerekli kılmaktadır. Ancak kırsal kesimdeki işletmelerin halen önemli bir kısmının geleneksel ve polikültür yapıda, ekonomik bilinçten uzak olmaları önemli bir eksiklik olarak karşımıza çıkmaktadır. Nitekim hayvancılık sektöründeki yapısal sorunlar, üreticilerin örgütlenme yetersizliği, girdilerin yüksek olması, ürünlerin pazarlanmasında yaşanan sorunlar üreticilerin mağdur olmasına neden olmaktadır (Aral ve Cevger 2000; Şahin ve ark. 2001; Günlü ve ark. 2006). Bu bakımdan sığırcılık işletmelerinde üretim maliyetlerini dikkate alan, üreticiye karlı ve verimli çalışma imkânı sağlayan fiyat ve pazar eksenli destekleme politikalarının etkin şekilde uygulamaya konulması gerekmektedir (Demir ve ark. 2014).

$\mathrm{Bu}$ araştırmada, Ordu ili sınırları içerisinde sığırcılık faaliyetinde bulunan işletmelerindeki hayvan varlığının ve önemli sorunların belirlenmesi amaçlanmıştır.

\section{Materyal ve Yöntem}

Ordu ilinde kayıtlı 42958 sığırcılık işletmesi bulunmakta olup (Türk-Vet Kayıt Sistemi 2016) araştırmanın materyalini bu işletmelerden tabakalı örnekleme yöntemine göre seçilen toplam 517 adet işletme oluşturmuştur. İşletmeler büyüklüklerine göre $\leq 5$ baş, 6-15 baş, 16-29 baş ve $\geq 30$ baş olmak üzere 4 farklı gruba ayrılmıştır. Örneğe girecek işletme sayıları \%1 hata payı

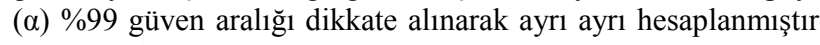
(Yamane 1967).

$$
n=\frac{N \sum N_{h} S_{h}^{2}}{N^{2} * D^{2}+\sum N_{h} S_{h}^{2}}, \quad D^{2}=\frac{d^{2}}{Z^{2}}
$$

Formülde;

$\mathrm{n}=$ Örnek hacmi

$\mathrm{N}=$ Populasyondaki toplam işletme sayısı

$\mathrm{N}_{\mathrm{h}}=\mathrm{h}$. tabakadaki işletme sayıs1

$\mathrm{S}_{\mathrm{h}}=\mathrm{h}$. tabakadaki standart sapma

$\mathrm{d}=$ Populasyon ortalamasından izin verilen hata miktarı

$\mathrm{Z}=$ İzin verilen hata miktarına göre Z-tablo değeridir.

Belirlenen örnek genişliğinin tabakalara dağıtımında orantılı dağıtım yöntemi kullanılmış ve aşağıdaki formül ile tabakaların genişlikleri hesaplanmıştır. Anketlerin değerlendirilmesinde SPSS İstatistik Paket Programı kullanılmıştır ( SPSS 2008).

$$
n_{h}=\left(\frac{N_{h}}{N}\right) n
$$

Formülde;

$\mathrm{n}_{\mathrm{h}}=\mathrm{h}$. tabakadaki anket sayis 1

$\mathrm{N}_{\mathrm{h}}=\mathrm{h}$. tabakadaki işletme sayısı

$\mathrm{N}=$ Toplam işletme sayısıdır.

\section{Bulgular ve Tartışma}

$\mathrm{Bu}$ araştırmada incelenen sığırcılık işletmelerinin tabakalara göre dağılımı Çizelge 1'de verilmiştir.
Çizelge 1. İşletmelerin tabakalara göre dağılımı.

Table 1. Distribution of enterprises by classification.

\begin{tabular}{lrr}
\hline Hayvan sayısı & $\mathrm{n}$ & $\%$ \\
\hline$\leq 5$ baş & 325 & 62.86 \\
$6-15$ baş & 137 & 26.50 \\
$16-29$ baş & 27 & 5.22 \\
$\geq 30$ baş & 28 & 5.42 \\
\hline
\end{tabular}

Çizelge 1'de görüldüğü üzere, araştırmada incelenen işletmelerden \%62.86's1 (325 işletme) $\leq 5$ baş, \%26.50'si (137 işletme) 6-15 baş, \%5.22'si (27 işletme) $16-29$ baş ve $\% 5.42$ 'si ise (28 işletme) $\geq 30$ baş hayvan sayısına sahiptir. Ordu ili genellikle engebeli arazi yapısına sahip olduğundan dolayı yeterli ekilebilir arazi bulunmamaktadır. $\mathrm{Bu}$ nedenle işletmelerin önemli bir kısmı küçük aile işletmeleri şeklinde olup 5 ve daha az hayvana sahiptirler. Alkan ve Ünlü (2019) Giresun ilinde yaptıkları çalışmada, işletmelerin \%91'inin 15 baş ve daha az sayıda hayvana sahip olan küçük aile işletmelerden ve geri kalanların ise 15 baş ve daha fazla hayvana sahip olan işletmelerden oluştuğunu belirtmiştir. Demir ve Ayvazoğlu (2012) tarafından Kars ilinde yapılan araştırmada ise işletme başına ortalama sı̆̆ır sayısı 8.2 baş olarak tespit edilmiştir. Kuşkusuz işletme büyüklükleri yatırılan sermayeye, işletmeden beklentilere ve bilgi birikimine bağlı olarak değişmektedir. $\mathrm{Bu}$ değerler hayvan varlığını belirleyen ana etmenlerdir. Güğercin ve ark. (2017) tarafindan yapılan bir araştırmada, incelenen sığırcılık işletmelerden \%30'unda hayvan varlığının 200 adetten fazla, \%20'sinde 101-200 arasında, \%30'unda 51-100 arasinda ve \%20'sinde ise 50 adetten az olduğu belirlenmiştir. Yine, Demir ve ark. (2014) tarafindan yapılan araştırmada, incelenen sığırcılık işletmelerinin \%26.5'inde 1-5 baş, \%29.6'sında 6-10 baş, $\% 27.8$ 'inde $11-20$ baş ve \%16'sında ise 21 baş ve daha fazla sağmal sığır bulunduğu saptanmıştır. Demir ve Aral (2009) yaptıkları bir çalışmada, inceledikleri sığırcılık işletmelerinin \%63.8'inin 1-10 baş sığıra sahip küçük ölçekli işletmelerden, $\% 28.8^{\prime}$ 'inin 11-20 baş sığır ile orta ölçekli işletmelerden ve \%7.5'inin 21-30 baş sığıra sahip büyük ölçekli işletmelerden oluştuğunu belirlemişlerdir.

Araştırmada incelenen sığırcılık işletmelerindeki sığır ırklarının dağılımı Çizelge 2'de verilmiştir.

Çizelge 2. Sığırcılık işletmelerdeki sığır ırklarının dağılımı.

Table 2. Distribution of cattle breeds in cattle enterprises.

\begin{tabular}{lrc}
\hline Sığır ırkları & $\mathrm{n}$ & \multicolumn{1}{c}{$\%$} \\
\hline Yerli Irklar & 163 & 31.53 \\
Melez ırklar & 233 & 45.07 \\
Kültür Irkları & 73 & 14.12 \\
Yerli ırklar + Melez ırklar & 6 & 1.16 \\
Melez + Kültür ırkları & 29 & 5.61 \\
Yerli + Melez + Kültür ırkları & 13 & 2.51 \\
\hline
\end{tabular}

Çizelge 2'de özetlendiği gibi, araştırmada incelenen işletmelerin \%45.07'sinde melez genotipler, \%31.53'ünde yerli sığır ırkları ve sadece \%14.12'sinde kültür ırkı sığırlar bulunmaktadır. Ordu ilindeki arazi yapısının engebeli olması nedeniyle özellikle iri yapılı kültür ırkı süt sığırlarının merada otlaması zor olduğundan işletmelerde yetiştirilen kültür 1rk1 sığır sayısı da azdır. Ancak, son zamanlarda artan suni tohumlama sayesinde melez sığırların sayısı arttı̆̆ından, işletmelerin önemli bir kısmında melez sığırlar 
kullanılmaktadır. Şeker ve ark. (2012), Muş ilinde yaptıkları araştırmada kültür ırklarından Esmer ve Simmental ırkın daha çok tercih edildiğini bildirmişlerdir. Şahin ve ark. (2001) tarafından Van ili ve ilçelerinde yapılan bir araştırmada, işletmelerin \%61.1'inde Sarı Alaca, \%33.5 'inde Siyah Alaca ve \%5.4'ünde ise Esmer 1rk kullanıldığ 1 tespit edilmiştir. İnan (1992) Tekirdağ ilinde yaptığı bir araştırmada, incelediği sığırcılık işletmelerindeki sığırların \%75'inin Siyah Alaca, $\% 20.8$ 'inin Montofon ve \%4.2'sinin ise melez genotiplerden oluştuğunu belirlemiştir.

Tekirdağ iline bağlı köylerdeki 46 süt üretim işletmesinde sı̆̆ırların \%75'inin Siyah Alaca, \%20.8'inin Montofon ve \%4.2'sinin ise karışı 1rklardan oluştuğu bildirilmiştir (İnan 1992). Demir ve ark. (2014) tarafindan yapılan araştırmada, incelenen sığırcılık işletmelerindeki sığırların \%38.3'ünün yerli ırk, \%34'ünün kültür+melez 1 rk ve $\% 27.8$ 'ininde yerli + melez genotiplerden oluştuğu belirlenmiştir. Yine aynı araştırmada, küçük ölçekli işletmelerde daha çok yerli ırk sığırların, büyük ölçekli işletmelerde ise kültür + melez 1rkı sığırların yoğun olarak bulunduğu saptanmıştır. Tutkun (1999) Diyarbakır ili merkez ilçesine bağlı köylerde 103 işletmede yaptığ araştırmada, işletmelerdeki sı̆̆ır varlığının Siyah Alaca (\%31.3), Siyah Alaca melezi (\%47.1), Esmer (\%0.3), Esmer melezi (\%0.4) ve yerli irklardan (\%20.81) oluştuğunu bildirmiştir. Ildız (1999) Tokat ilinde ithal sığır yetiştiren işletmelerde yaptığı araştırmada, işletmelerde yetiştirilen toplam sığır varlı̆̆ının çoğunluğunun (\%55.23) Esmer 1rk sığırlardan oluştuğunu ve bu işletmelerin \%17.78'inde $1-5$ baş, \%44.44'ünde 6-10 baş ve \%37.78'inde 11 baş sığır bulunduğunu tespit etmiştir.

Araştırmada incelenen sığırcılık işletmelerinde belirlenen önemli sorunların dağılımı Çizelge 3'de verilmiştir.

Çizelge 3. Sı̆̆ırcılık işletmelerinin en önemli sorunları.

Table 3. The most important problems of cattle enterprises.

\begin{tabular}{lrr}
\hline Sorunlar & $\mathrm{n}$ & \multicolumn{1}{c}{$\%$} \\
\hline Ürünlerin fiyatına pazarlanmaması & 178 & 34.43 \\
Yem fiyatlarının yüksek olması & 251 & 48.55 \\
$\begin{array}{l}\text { Sağlık-koruma hizmetleri } \\
\text { Ürünlerin fiyatına pazarlanamaması+Yem }\end{array}$ & 3 & 0.58 \\
$\begin{array}{l}\text { fiyatlarının yüksek olması } \\
\text { Ürünlerin fiyatına pazarlanamaması + Sağlık- }\end{array}$ & 59 & 11.41 \\
$\begin{array}{l}\text { koruma hizmetleri } \\
\text { Yem fiyatlarının yüksek olması + Sağlık-koruma }\end{array}$ & 1 & 0.19 \\
$\begin{array}{l}\text { hizmetleri } \\
\text { Ürünlerin fiyatına pazarlanamaması+ Yem } \\
\text { fiyatlarının yüksek olması+ Sağlık-koruma }\end{array}$ & 11 & 2.13 \\
hizmetleri & 14 & 2.71 \\
\hline
\end{tabular}

Çizelgede görüldüğü gibi, işletmelerin $\% 48.55$ 'inde önemli sorunun yem fiyatlarının yüksek olması, \%34.43 ünde ise ürünlerin değer fiyatına pazarlanamaması olarak belirlenmiştir. Öztürk ve Karkacıer (2008) yaptıkları bir araştırmada, sığırcılık işletmelerinin en önemli sorunlarını pazar, kredi, yem fiyatının yüksekliği ve süt fiyatının düşüklüğü olarak belirlemişlerdir. Ankete katılanların neredeyse yarısı yem fiyatlarının yüksek olmasını en büyük sorun olarak gördüklerini belirtmişlerdir. Çünkü çoğu işletmeler kendi öz imkânları ile işletmeyi yürüttükleri için gelirlerinin çoğunu yem parası olarak harcamaktadırlar. Özellikle kış aylarında hayvanlar bahçelere çıkıp otlayamadığı ve ahırda kaldıklarından bu masraf daha fazla olmaktadır. Ayrıca elde dilen ürünlerin değer fiyatından daha düşüğe pazarlamaları işletme sahiplerinin işini daha da zorlaştırmaktadır. Ağrı ilinde yapılan bir araştırmada, sığırcılık işletmelerinin ana sorunları sırasıyla hastalıklar (\%49.58), pazar (\%48.74) ve süt fiyatı (\%1.68) olarak belirlenmiştir (Bakan ve Aydın 2016). Şahin ve Gürsoy (2016) tarafindan yapılan araştırmada, sığırcılık işletmelerinde görülen sorunlar arasında ilk sırayı \%75.58 ile yem fiyatlarının yüksekliği alırken, bunu $\% 68.60$ ile yaylaların kurak ve yetersiz olmas1, \%33.72 ile hayvanları ucuz olması, \%30.23 ile yem bitkisi yetiştirememe ve $\% 15.12$ ile bakım masraflarının yüksek olmasının izlediği saptanmıştır. Konuyla ilgili yapılan diğer araştırmalarda sığırcılık işletmelerinin sorunları süt fiyatının düşük olması, yem giderlerinin yüksek olması, pazarlamada yaşanan sıkıntılar, hastalıklar, veteriner hizmeti ve ilaç giderlerinin yüksek olması seklinde olduğu belirlenmiştir (Akkuş 2009; Özduran 2011; Şeker ve ark. 2012; Koçyiğit ve ark. 2016; Şahin ve Gürsoy 2016).

\section{Sonuç}

Ordu ilinde faaliyet göstermekte olan sığırcılık işletmelerinde hayvanların verimlerinin arttırılabilmesi, kaliteli ürün elde edilebilmesi ve üretimde sürdürülebilirliğin sağlanabilmesi için;

- Sığırcılık yapan işletmelerde verimi arttırmanın en önemli yollarından biri yüksek verimli ırklarla çalışmaktır. İncelen işletmelerde yüksek sayılabilecek oranda (\%31.53) verim özellikleri kültür ırkı ve melezlerine oranla düşük olan yerli ırk kullanılmaktadır. $\mathrm{Bu}$ nedenle de verimin arttırılması ve buna bağlı olarak ta üretimde sürdürebilirliğinin sağlanabilmesi için özellikle işletmelerdeki kültür 1rkı ve melez genotiplerin oranı arttırılmalıdır.

- Sığır yetiştiriciliğinde kaliteli ürün elde etmek kadar, elde edilen ürünün değerine satılması da büyük bir önem arz etmektedir. Bu nedenle de, yetiştiricilerin elde etikleri ürünleri değer fiyatına satabilmeleri ve pazarlama sorunu yaşamamaları için birlikte hareket etmelerini (örgütlenmeleri) sağlayacak eğitim çalışmaları yapılmalı ve tarımsal örgütlenme teşvik edilmelidir.

- Sığırcılık işletmelerinde karşılaşılan yüksek üretim maliyeti ve yem fiyatlarının yüksekliği bu işletmeler için büyük sorun oluşturmaktadır. Bu sorunun çözülmesi ya da mümkün olduğu kadar azaltılması için yem bitkileri üretimi sığırcılık işletmelerinde yapılmalıdır. Sığırcılık işletmelerinin yeterli arazisi yok ise yem bitkisi üreten işletmeler ile sözleşme yapılarak ihtiyaç duyulan yem bitkisi daha ucuza alınmalıdır. Bunun uygulanabilmesi için de yem bitkileri yetiştiriciliğinin yeterince desteklenmesi gerekmektedir.

- Sığır yetiştiriciliği yapmakta olan ve yetiştiriciliğe başlamak isteyen yetiştiricilerin düşük faizli yatırım ve işletme kredisi kullanabilmeleriyle ilgili yasal düzenlemeler getirilmeli ve kolaylıklar sağlanmalıdır.

\section{Teşekkür}

Ordu Üniversitesi Bilimsel Araştırma Projeleri Yönetim Birimi'ne sağlamış oldukları maddi destekleri için teşekkür ederiz (Proje No: BY-1706).

\section{Kaynaklar}

Akkuş Z (2009) Konya ilindeki süt sı̆̆ırcılı̆̆ı işletmelerinin yapısal özellikleri. Yüksek Lisans Tezi. Selçuk Üniversitesi Fen Bilimleri Enstitüsü, Konya. 
Alkan S, Güney Z (2019) Ordu ili sığırcılık işletmelerinin yapısal özelliklerinin belirlenmesi. Mediterranean Agricultural Sciences 32(3): 447-452.

Alkan S, Ünlü H (2019) Giresun ilindeki sığırcılık işletmelerinin genel yapısının belirlenmesi. Mediterranean Agricultural Sciences 32(1): 109-115.

Aral S, Cevger Y (2000) Türkiye'de Cumhuriyet'ten günümüze izlenen hayvancılık politikaları. Türkiye 2000 Hayvancılık Kongresi, Kizılcahamam, Ankara.

Bakan Ö, Aydın R (2016) Ağrı ili süt sığırcılı̆̆ı işletmelerinin sosyoekonomik özellikleri. Atatürk Üniversitesi Ziraat Fakültesi Dergisi 47(2): 113-122.

Demir P, Aral S (2009) Kars ilinde faaliyet gösteren süt sığırcılığı işletmelerinin karşılaştıkları sorunlar ve çözüm önerileri. Veteriner Hekim Derneği Dergisi 6(1): 47-54.

Demir P, Ayvazoğlu C (2012) Hayvancılık işletmelerinin veteriner hekimlik hizmetlerinden beklentileri: Kars ili örneği. Erciyes Üniversitesi Veteriner Fakültesi Dergisi 9(3): 169-174.

Demir P, Aksu Elmalı D, Işık S, Tazegül R, Ayvazoğlu C (2013) Kars ili süt sığırcılık işletmelerinde yem kullanımı ve hayvan sesleme alışkanlıklarının ekonomik önemi. Atatürk Üniversitesi Veteriner Bilimleri Dergisi 8(3): 229-236.

Demir P, Aral Y, Sarıözkan S (2014) Kars ili süt sığırcılık işletmelerinin sosyo-ekonomik yapısı ve üretim maliyetleri. Yüzüncü Y1l Üniversitesi Veterinerlik Fakültesi Dergisi 25(1): 1-6.

Güğercin Ö, Koç DL, Büyüktaş K, Baytorun N, Polat B, Polat ÖD (2017) Adana ilinde bulunan bazı süt sığırcılığı işletmelerindeki hayvan barınaklarının mevcut durumlarının belirlenmesi. Çukurova Tarım Gida Bilimleri Dergisi 32: 19-28.

Günlü A, Atasever M, Karakaya Y (2006) Erzurum ili hayvancılığının yapısal özellikleri ve yakın gelecekteki durumu üzerine genel değerlendirme. Atatürk Üniversitesi Veteriner Bilimleri Dergisi 1(3-4): 55-68.

Ildız F (1999) Tokat ili merkez ilçesinde ithal sığır yetiştiren tarım işletmelerinin yapısı. Yüksek Lisans Tezi. Ankara Üniversitesi, Fen Bilimleri Enstitüsü, Zootekni Anabilim Dalı, Ankara.

İçöz Y (2004) Bursa ili süt sığırcılık işletmelerinin kârlılık ve verimlilik analizi. Yayın No: 116, Ankara.
İnan H (1992) Tekirdağ ili süt sığırcılığı işletmelerinin doğrusal programlama yöntemi ile planlanması ve planlı çalışmanın işletme gelirine etkisi. Trakya Bölgesi I. Hayvancılık Sempozyumu, Tekirdağ.

Koçyiğit R, Diler A, Yanar M, Güler O, Aydın R, Avcı M (2016) Süt sığırcılığ işletmelerinde hayvan sağlığı, veteriner sağlık hizmetleri ve yetiştirici memnuniyeti: Erzurum ili Hınıs ilçesi örneği. Türk Tarım ve Doğa Bilimleri Dergisi 3(1): 24-32.

Özduran H (2011) Zonguldak ili damızlık sığır yetiştiricileri birliğine üye olan ve olmayan işletmelerin sosyal ve ekonomik yönden incelenmesi: Çaycuma örneği. Yüksek Lisans Tezi, Çanakkale Onsekiz Mart Üniversitesi, Fen Bilimleri Enstitüsü, Tarım Ekonomisi Ana Bilim Dalı, Çanakkale.

Öztürk D, Karkacıer O (2008) Süt sı̆̆ırcılığı yapan işletmelerin ekonomik analizi (Tokat ili Yeşilyurt ilçesi örneği). Gaziosmanpaşa Üniversitesi Ziraat Fakültesi Dergisi 25(1): 15-22.

SPSS (2008) SPSS Statistics for Windows, Version 17.0. Chicago: SPSS Inc.

Şahin K, Gül A, Koç B, Dağıstan E (2001) Adana ilinde entansif süt sığırcılığı üretim ekonomisi. Yüzüncü Y1l Üniversitesi, Ziraat Fakültesi Tarım Bilimleri Dergisi 11(2): 19-28.

Şahin K, Yılmaz İH (2008) Van ili Gürpınar ilçesinde yem bitkileri üretimi ve sorunları üzerine bir araştırma. Ankara Üniversitesi Ziraat Fakültesi Tarım Bilimleri Dergisi 14(1): 16-21.

Şahin K, Gürsoy AK (2016) Iğdır ili süt sığırcılığı işletmelerinin sosyoekonomik yapısı. Nevşehir Bilim ve Teknoloji Dergisi TARGID Özel Say1: 118-129.

Şeker İ, Tasalı H, Güler H (2012) Muş ilinde sığır yetiştiriciliği yapılan işletmelerin yapısal özellikleri. Fırat Üniversitesi Sağlık Bilimleri Veteriner Dergisi 26(1): 09-16.

Tutkun M (1999) Diyarbakır ili merkez ilçeye bağlı köylerdeki süt sığırcılığının yapısı. Yüksek Lisans Tezi, Ankara Üniversitesi Fen Bilimleri Enstitüsü, Ankara.

Türk-Vet Kayıt Sistemi (2016) Tarım ve Orman Bakanlığı hayvan bilgi sistemi, Türk-vet kayıt sistemi Ordu ili verileri.

Yamane T (1967) Statistics, An Introductory Analysis. 2nd Ed. New York: Harper and Row. 